\title{
As REPERCUSSÕES MIDIÁTICAS SOBRE A LEI 10.639/03 EM SALVADOR-BA: UMA ANÁLISE DAS IMPLICAÇÕES NA PRÁXIS PEDAGÓGICA*
}

\author{
AnÁlia de Jesus Moreira, \\ da Universidade Federal da Bahia e da Universidade \\ Federal do Recôncavo da Bahia
}

\begin{abstract}
Resumo: o presente texto ${ }^{1}$ aborda as repercussões na mídia baiana acerca do processo de implementação obrigatória da Lei 10.639/03 nos currículos das escolas de ensino fundamental e médio. Após clipagem ${ }^{2}$, analisa alguns textos de reportagens publicadas em dois dos mais importantes jornais eletrônicos em Salvador, "ibahia" e "A Tarde on line". As reportagens destacam a situação das escolas baianas diante da investida do Ministério Publico da Bahia na fiscalização do cumprimento da lei e que gerou uma situação intervencionista e tensa. Este texto propõe refletir sobre o episódio, mostrando que a desigualdade social e racial reproduzida na escola mantém-se inalterada. Em outro ponto, sugere refletir sobre a importância de se combater toda forma de discriminação e preconceito na escola e fora dela, fatores abordados pela grande imprensa como reflexo da lei 10.639/03.
\end{abstract}

Palavras-chave: Escola. Legislação. Mídia.

\section{INTRODUÇÃO}

A Lei ${ }^{3} n^{\circ} 10.639 / 03$, que obriga o ensino da história e da cultura africanas e afro-brasileiras no currículo oficial das redes de ensino em todo o Brasil, provocou grande focalização midiática em Salvador, cidade de maior população afrodescendente do país: $85 \%$ da população total, segundo números do IBGE de 2007. O foco da mídia dirigiu-se prioritariamente à escola,

\footnotetext{
* Constitui a lista dos artigos vencedores do Concurso Nacional de Artigos Científicos e Ensaios Teóricos Sobre Educação para a Diversidade e Enfrentamento às Desigualdades no Contexto Brasileiro, Edital n 01/2010 ANPEd/SECAD. Recebido pela Inter-Ação em 27/05/2011.
} 
alvo da Lei. Observo que, em seu processo histórico, a escola tem detido, em termos midiáticos, uma imagem opaca e normal, ${ }^{4}$ resumida quase sempre a notícias sobre número de vagas, problemas de estrutura física ou conflitos violentos, entre alunos, professores e comunidades, focos que considero do ponto de vista midiático, de interesse apenas momentâneo, pois raramente são alvos de recursos, de repercussão ou de debates.

O motivo principal do interesse dos meios de comunicação de massa no foco que proponho refletir neste texto está na tensão que a Lei 10.639/03 provoca no ambiente ${ }^{5}$ escolar e nos prenúncios de que o termo lei deva cumprir-se altivo na obediência civil. O foco da mídia, entretanto, centra-se justamente no oposto dessa obediência comum, significando dizer que a resistência da própria escola em aplicar a Lei, de forma não ingênua, atraiu a imprensa.

Trato especialmente da educação formal por entender que é esse campo o foco da Lei e compreendo a educação formal como algo que não significa simplesmente uma oposição à educação não-formal, no sentido político e cultural, como afirma Gadotti:

educação formal tem objetivos claros e específicos e é representada principalmente pelas escolas e universidades. Ela depende de uma diretriz educacional centralizada a exemplo do currículo. [...] Portanto, é a escola um espaço dependente de estruturas hierárquicas e burocráticas, controladas e fiscalizadas pelo poder central, o governo; enquanto educação não-formal [...] é mais difusa, menos hierárquica e menos burocrática, portanto, menos controlada. (GADOTTI, 2005, p. 1)

Acredito ser necessária a comparação de conceitos sobre educação formal e não-formal para que se perceba a importância de a Lei no 10.639/03 ser difundida, aplicada e refletida para além das concepções escolásticas, embora meu foco de análise seja a educação formal e a relação dela com a mídia. É preciso então, destacar a Lei 10.639/03 como instrumento legislativo de grande impacto sobre a execução de políticas públicas e a rotina pedagógica em nosso país. Bastante sucinta para a tradição legislativa brasileira, essa lei se estabelece nos seguintes artigos:

Art. $1^{\circ}$ A Lei № 9.394, de 20 de dezembro de 1996, passa a vigorar acrescida dos seguintes arts. 26-A, 79-A e 79-B:

Art. 26-A. Nos estabelecimentos de Ensino Fundamental e [Ensino] Médio, oficiais e particulares, torna-se obrigatório o ensino sobre História e Cultura Afro-Brasileira. 
$\S 1^{\circ} \mathrm{O}$ conteúdo programático a que se refere o caput deste artigo incluirá o estudo de História da África e dos Africanos, a luta dos negros no Brasil, a cultura negra brasileira e o negro na formação da sociedade nacional, resgatando a contribuição do povo negro nas áreas social, econômica e política pertinentes à História do Brasil.

$\S 2^{\circ}$ Os conteúdos referentes à História e Cultura Afro-Brasileira serão ministrados no âmbito de todo o currículo escolar, em especial nas áreas de Educação Artística e de Literatura e História Brasileiras.

Art. 79-B. O calendário escolar incluirá o dia 20 de novembro como "Dia Nacional da Consciência Negra".

Art.2 ${ }^{\circ}$ Esta Lei entra em vigor na data de sua publicação.

Brasília, 9 de janeiro de 2003; $182^{\circ}$ da Independência e $115^{\circ}$ da República. (BRASIL, 2003)

Promulgada no ano de 2003, a Lei 10.639/03 objetiva atingir o currículo e o projeto político-pedagógico por se constituírem estes em poderosos instrumentos da cultura e da política escolares. Não entrarei no mérito da discussão sobre a necessidade de um instrumento vertical de poder para horizontalizar saberes diversos e tratar de identidades e diferenças; contudo, atento para o fato de que a escola é institucionalizada como local onde as relações sociais assimétricas devem ser problematizadas, refletidas e ampliadas.Meu objetivo é entender o interesse da grande mídia nesse momento vigoroso da educação brasileira, provocado pela obrigatoriedade da escola de "ensinar e aprender" cultura afro-brasileira e indígena.

\section{A LEI No 10.639/03: PRESSUPOSTOS E PROPOSTAS PARA A EDUCAÇÃO BRASILEIRA}

A Lei no 10.639, promulgada em 09 de janeiro de 2003, surgiu do Projeto de Lei no 259 de 1999, de autoria dos deputados Pilar Esther Grossi (PT-RS) e Benhur Ferreira (PT-MS), substitutivo do Projeto de lei do deputado Humberto Costa. A lei alterou a LDBEN n 9394/96, os Parâmetros Curriculares Nacionais e tornou obrigatório o ensino da História e Cultura Africana e Afro-Brasileira nas escolas de Ensino Fundamental e Ensino Médio de todo o país, configurando-se, atualmente, em instigante fonte de debates, por colocarem no centro da discussão nossas etnicidades. A proposta é problematizar questões identitárias, como a ancestralidade e a cultura, sugerindo para esses pilares a utilização de novas matrizes teóricas, que contemplem outros olhares sobre o processo histórico da cultura afro-brasileira.

Em 10 de março de 2008, foi assinada a Lei no 11.645/08 para, também, incluir, como obrigatórias no ensino básico, a história e a cultura dos 
índios brasileiros. Sem revogar a Lei no 10.639/03, a Lei n 11.645/08 reitera a atenção para a significação étnico-racial indígena ao lado dos povos africanos na formação do povo brasileiro. A prova dessa evidência está na necessidade emergente de aperfeiçoamento docente, intervenção na escola e reflexão no âmbito da sociedade como um todo, conforme preconizou a parecerista da Lei no 10.639/03, Petronília Beatriz Gonçalves Silva. Defende a autora que está na hora de abolir os sentimentos de superioridade e de inferioridade presentes na sociedade brasileira para que "novas formas de pessoas negras e não-negras se relacionarem sejam estabelecidas.

A Lei n 10.639/03 não se configura como obrigatória nos níveis extremos do ensino brasileiro, a Educação Infantil e a Educação Superior, e também não se assume categoricamente na educação não-formal, embora as Diretrizes Curriculares Nacionais orientem no sentido de que se promova a difusão da Lei em todos os níveis de ensino. Na Educação Infantil, considero equivocada a não obrigatoriedade da lei, uma vez que se trata do primeiro nível instituído de ensino.

Dessa maneira, compreendo que a ausência categórica da lei na formação de professores implica o risco de manter na superfície as bases epistemológicas e metodológicas dos temas propostos. Em meu entendimento. essa questão amplia a não institucionalização dos conhecimentos e saberes notadamente importantes para o processo de ampliação e diversificação da epistemologia acadêmica e da formação inicial de professores, a exemplo das vivências quilombolas, das culturas populares do corpo e movimento de origem indígena e africana, suas representatividades e sentidos.

\section{O PANORAMA ATUAL: TENSÕES E DESAFIOS NA ESCOLA}

Decorridos sete anos da promulgação da Lei no 10.639/03, ainda estamos impactando o documento no fato de que o termo lei aplicado ao significado de sistema vertical e normativo necessita ser amplamente debatido, sob pena de tornar inócuo seu efeito mais esperado: intervir na educação e provocar mudanças sociais. Em todo o país, a aplicabilidade da lei vem exigindo mobilizações emergentes, visando à difusão do documento, bem como o aperfeiçoamento docente. A esse respeito, recorro a Dávila (2006), para lembrar o fato histórico que marcou a formação de professores nas décadas de 30 e 40. Segundo esse autor, nesse período, era política de Estado prover o embraquecimento da pedagogia:

Os reformadores educacionais brasileiros buscavam um quadro de professores que fosse moderno, profissional, científico e representativo do ideal da 
classe média. Suas políticas foram bem sucedidas em produzir o quadro de professores que os reformadores educacionais imaginavam, e esse quadro de professores era quase exclusivamente branco. (DÁvILA, 2006, p. 420).

Por tal reflexão, reitero que o que está em jogo é a história da escola brasileira relacionada à sua disposição etnocêntrica. Refiro-me às práticas racistas, de negações gestuais, corporais e estéticas afrodescendentes que produziram na pedagogia efeitos embranquecedores, envolvendo também a formação docente.

INTERESSE dA Mídia NA LeI 10.639/03, A INTERVEnÇão do Ministério PúBlico NAS ESCOLAS: PERFIL DO PÚBLICO ALVO OU MERO SENSACIONALISMO?

Quando McLuhan ${ }^{6}$ afirmou no artigo Mutation7 que "a escola-clausura está a ponto de tornar-se escola abertura, ou seja, escola planetária, revelou também a tendência dos meios de comunicação de se atrelarem ao cotidiano escolar, possibilitando a denúncia e uma massa de informações diversas.

As previsões de McLuhan se concretizam em nossos dias quando os interesses da grande mídia e não apenas da mídia alternativa ${ }^{8}$ se constituem em fontes poderosas de informações, estabelecendo uma nova relação formativa e informativa, portanto pedagógica, entre escola e sociedade. Não obstante, reitero as ideologias dos meios de comunicação de massa no Brasil, apoiadas no poder político e econômico que historicamente facilitaram aos canais de televisão e às emissoras de rádio se concentrarem nas mãos de pequenos grupos articulados, atendendo a interesses corporativos.

Compreendo, entretanto, que os interesses sensacionalistas da grande mídia são proporcionais aos impactos que determinados assuntos assumem em nosso cotidiano. Dessa forma, defendo que o poder impactante da lei 10.639/03 extrapolou a substância sensacionalista da mídia e se firmou no interesse genuíno do publico alvo: a sociedade baiana cujas classes, pobres e ricos, estão representadas ou sintetizadas na escola. Mas, por que a lei 10.639/03 assume interesse tão grandioso na mídia neste momento?

Primeiro, é preciso articular um pensamento sobre as realidades ${ }^{9}$ de Salvador, cidade com $85 \%$ de sua população total formada por afrodescendentes e que detém o segundo menor PIB do Brasil, (IBGE, 2005), e campeã em desigualdades sociais. Depois, é preciso refletir sobre os papéis da escola, suas representatividades, práticas, culturas e ideologias.

Números do IBGE relativos ao $\mathrm{PIB}^{10}$ mostram que Salvador é a penúltima colocada no ranking de capitais em renda per capita do país. Entre os 5.560 municípios pesquisados, a capital baiana ficou atrás apenas de Teresina, 
capital do Piauí. A pesquisa mostra que a soma dos bens e serviços dividida pelo número de habitantes de Salvador foi de $\mathrm{R} \$ 4.624$ para uma média nacional de $\mathrm{R} \$$ 8.694. O quadro em branco e preto se agrava mais ainda quando o parâmetro é a pesquisa do PNUD ${ }^{11}$. Essa breve análise quer, objetivamente, problematizar o entrelaçamento entre pobreza e nível educacional na capital dos baianos.

Dados referentes a Salvador, coletados em 2005 pela Companhia de Desenvolvimento Urbano do Estado da Bahia (CONDER), confirmam que a Região Metropolitana de Salvador é a mais desigual entre todas as regiões do país. Um dos resultados mostra que um morador de área nobre ${ }^{12}$ ganha em média 25 vezes a mais do que, por exemplo, um homem residente no subúrbio ferroviário, que é uma das regiões mais pobres da capital baiana. Esses dados de cunho econômico e social são refletidos na questão da educação. Enquanto no Itaigara, o índice de analfabetos é de 0,93\%, em Coutos, o índice chega a 12\%. Enquanto em Coutos, $82,70 \%$ das pessoas em idades entre 7 e 14 anos estão na escola, no Itaigara esse número sobe para 97,67\%. Portanto, a Lei 10.639/03 como política pública é de grande interesse para a maioria da população de Salvador. A grande mídia sabe disso porque, ao produzir e comercializar informações gera grandes lucros para grupos mais favorecidos economicamente e socialmente, em detrimento de uma massa excluída e invisibilizada, que não dispõe sequer de dados sobre sua própria existência social e econômica.

Sobre a escola, é preciso entendê-la como local onde potencialmente as culturas se encontram e se confrontam. Reporto-me a visão de Peter McLaren, (1977) pra quem a "política cultural está presente na escolarização para legitimar o poder e assim reproduzir desigualdades como o racismo e o sexismo, fragmentando relações sociais democráticas e promovendo a competitividade e o etnocentrismo". (p.13) Interpreto tais diagnósticos de McLaren como estratégias capitalistas abusivas para garantir a manutenção das desigualdades e fortalecer seus domínios. Esses olhares possibilitam reflexões várias sobre as reportagens publicadas em 2007 pelo jornal $A$ Tarde on line de Salvador.

A primeira reportagem da série assinada pelo jornalista Victor Pamplona informa da decisão do Ministério Público da Bahia de fiscalizar os projetos políticos pedagógicos que não estão contemplando a Lei. Sob o título "Escolas privadas não temem inquérito do MP", o jornalista revelou:

O cumprimento da Lei 10.639/2003 pelas escolas baianas entrou na agenda do Ministério Público estadual na última semana. Os promotores Almiro Sena (Combate à Discriminação) e Márcia Virgens (Defesa da Educação) se 
reuniram com representantes de 24 instituições particulares de Salvador para pedir que, até a próxima quarta-feira, 16 de maio, encaminhem ao MP o plano político-pedagógico adotado por elas.. (PAMPLONA, 12/05/2007).

A série jornalística oferece indagações sobre a motivação para a resistência à lei, especialmente na rede estadual e na rede privada. Na busca da explicação, confrontei-me mais uma vez com as abordagens sobre as bases formativas da educação brasileira ligadas à questão do preconceito e da discriminação racial no Brasil.

Tal ideologia, de bases eugenistas e higienistas, também foi responsável por valorizar os estereótipos racistas e a construção da identidade estigmatizada estritamente ligados à questão do preconceito e da discriminação racial no Brasil, e embutidos no próprio processo de aquisição do termo raça ${ }^{13}$, do senso comum para "naturalizar" o preconceito e a discriminação racial. Isto se concretiza no rechaçar o termo raça como de origem ideológica surgido das bases da luta dos movimentos negros e ao mesmo tempo na reiteração de sua negação como diferenciação biológica. Dessa forma, engrendram-se explicações cordiais de recalques e de tolerância para os atos de racismo, em vez de assumi-los como criminosos.

Outra parte da reportagem revela possíveis motivos que teriam levado a chamada grande imprensa a se interessar por um assunto da área educacional somente a partir do momento em que o Ministério Público Estadual da Bahia decidiu acompanhar e fiscalizar a rotina de grandes escolas da rede privada em Salvador onde existe maior resistência à difusão da Lei.

Explicito que a rede privada em Salvador é a segunda mais numerosa em alunos e professores, atendendo a cerca de 300 mil estudantes e empregando mais de 15 mil professores, números esses conferidos pelo Sindicato dos Professores da Rede Privada. A estadual é a maior rede com cerca 500 mil alunos e 30 mil professores. A municipal que atende somente alunos da Educação Infantil e do Ensino Fundamental se constitui na menor rede, com cerca de 170 mil alunos e sete mil professores. Na mesma reportagem, é revelada a fonte da informação que gerou a reportagem: constatou-se que a comunidade escolar recorreu à grande mídia.

Têm chegado ao nosso conhecimento notícias de escolas que estão dificultando a implantação das mudanças. O fato de a Bahia não ter regulamentado a lei não serve como desculpa, pois desde 2004 o Conselho Nacional da Educação divulgou as diretrizes para todo o País", diz Almiro Sena. "Depois da entrega dos projetos, vamos criar uma comissão de especialistas para avaliá-los.. Em seguida, ouviremos alunos e professores sobre a implantação das medidas na prática". Em escolas privadas da capital, a iniciativa do Ministério 
Público foi recebida sem receio. “O tema já é abordado por nós desde 2005, no espírito da lei, mostrando a cultura afro integrada à cultura brasileira", diz o diretor pedagógico do Colégio Módulo, Jayme Sodré - integrante do Conselho Estadual da Educação. "Nossos professores estão preparados, mas continuamos incentivando o aprofundamento. (PAMPLONA, 12/05/2007).

Polarizando fontes, a exemplo da Associação dos Professores Licenciados da Bahia, APLB, e diretor de escola privada, o jornalista Pamplona buscou outras explicações para a resistência da rede particular em promover a lei 10.639/03, o que deu à reportagem um teor de articulação entre a linguagem objetiva e popular que caracteriza os meios de massa e as reflexões com respaldo político e histórico, marcas de informações mais consistentes, a exemplo dos artigos jornalísticos.

Esse processo envolve quebra de cultura e três anos é pouco", acredita o diretor. Para o coordenador-geral da APLB (Sindicato dos Trabalhadores em Educação do Estado da Bahia), Rui Oliveira, a maioria das escolas particulares, no entanto, tem utilizado apenas "maquiagem" ou "perfumaria" no ensino da cultura afro. "Para combater isso, queremos a inclusão da temática no vestibular da UFBA e das universidades estaduais. Só então as escolas darão o devido valor à questão", diz. O diretor do Anchieta tem outra explicação: "Existem escolas preocupadas com o tema, mas outras, é verdade, nunca fizeram nada. O problema é que o próprio Estado não dá o exemplo. (PAMPLONA, 12/05/2007)

Na mesma reportagem é feito um elogio à Rede Municipal de Ensino de Salvador, que primeiro iniciou a instrumentalização dos professores para o efetivo cumprimento da Lei 10.639/03. Na rede privada e na rede estadual de ensino, comparativamente maiores do que a rede municipal em número de alunos, professores e funcionários, o processo é lento, motivando a intervenção inusitada do Ministério Público. Coincidência ou não, após as primeiras denúncias de $A$ Tarde On Line, alguns resultados começaram a aparecer. $\mathrm{O}$ primeiro deles foi a resolução do Conselho Estadual de Educação que, de forma atrasada, enfim deu resposta.

Estado brasileiro onde a herança cultural africana mais fincou raízes, a Bahia começa na próxima semana a tentar recuperar o tempo perdido com a inexistência de uma política para implantar o ensino da cultura e história afro-brasileira em suas escolas. Com mais de quatro anos de atraso em relação à aprovação da Lei federal 10.639/2003, que determinou a inclusão do tema nos currículos escolares brasileiros, o Conselho Estadual da Educação publica a resolução 15/2007 no Diário Oficial deste sábado, regulamentando as mudanças no sistema estadual de ensino. Nela estão as diretrizes a 
serem seguidas pelas escolas públicas e privadas do Estado para cumprir o objetivo da lei: incluir em todas as matérias, sobretudo História, Educação Artística e Literatura, "o estudo da História da África e dos africanos, a luta dos negros no Brasil, a cultura negra brasileira e o negro na formação da sociedade nacional". Segundo a presidente do conselho, Renée Albagli Nogueira, a demora foi decorrência da própria lei, "que não determina prazo" para introduzir as modificações. "Mas, logo no início de meu mandato, em julho de 2006, instituí uma comissão para cuidar do assunto", argumenta, procurando mostrar que, sob sua batuta, o conselho jamais fechou os olhos para a questão. (PAMPLona, 12 de maio de 2007).

O caráter imediato da resolução do Conselho Estadual da Educação trouxe à tona o poder de denúncia exercido pela comunidade escolar por meio da grande mídia, um fenômeno abordado por Laurício Neumann, 1990, ao analisar papel dialógico dos meios de comunicação de massa (rádio, cinema, jornais, outdoors e Internet).

No dia 21 de novembro de 2007, a assessoria de imprensa do Ministério Público da Bahia enviou às redações dos jornais e emissoras de radiodifusão uma produção sobre as visitas do MP às escolas particulares, muitas delas acompanhadas de jornalistas, um efeito de pré-pauta ${ }^{14}$ que inspira o caráter sensacionalista. A matéria de fonte oficial, sem assinatura pessoal, foi reproduzida na íntegra pelo site ibahia.

Em janeiro do próximo ano, o Ministério Público Estadual, através do Grupo de Atuação Especial em Defesa da Educação (Geduc), irá propor a assinatura de um Termo de Ajustamento de Conduta (TAC) às escolas particulares de Salvador, para que seja implantado o ensino da história e cultura afro-brasileira em suas grades curriculares. A decisão foi tomada durante uma audiência pública realizada esta semana pelo Geduc.Também na reunião, presidida pela coordenadora do grupo, promotora de Justiça Márcia Virgens, ficou instituído que os peritos da Universidade Federal da Bahia (UFBA), professor Ubiratan Castro, da Universidade Estadual da Bahia (UNEB), professora Sueli Santana, e do Sindicato dos Professores da Bahia (Sinpro), professoras Marli Souza e Heloisa Monteiro, irão analisar os projetos pedagógicos das instituições privadas. Para a representante do Ministério Público, a implantação da Lei 10.639/03, que determina o ensino da história afro-brasileira nas escolas, "é muito importante" pois objetiva o combate ao racismo e à exclusão no processo educativo. Participaram da audiência professores e representantes de colégios particulares de Salvador, os quais tiveram oportunidade de tirar dúvidas e debater sobre a implementação da Lei nas instituições privadas de ensino.(IBAHIA, 21/11/2007). 
A investida do Ministério Público baiano junto às escolas, especialmente as particulares, deu visibilidade à Lei 10.639/03, provocando novas reações, desta vez em nível governamental. Durante reunião extraordinária do Conselho Nacional de Educação em Salvador, no dia 20 de fevereiro de 2008, foi divulgada a proposta da Câmara de Educação Básica, de criação de um sistema para avaliar a implementação da Lei 10.639/03 em todo o país, com atenção especial para Salvador. A reportagem da Jornalista lonice Lorenzoni, assessora do Conselho Nacional, descreveu o cerco estendido aos estados e municípios.

Uma das ações, explica a presidente da Câmara de Educação Básica, Clélia Brandão Craveiro, será acompanhar a implantação das diretrizes nacionais nos sistemas de ensino. O primeiro passo de cada estado e de cada município será regulamentar a aplicação da lei, que significa dizer como e em que áreas do conhecimento serão oferecidos os conteúdos. Segundo Clélia Brandão, as diretrizes, elaboradas pelo CNE, em 2004, oferecem o caminho a ser seguido pelas redes públicas e privadas. "Não se trata de criar nova disciplina no currículo, mas inserir os conteúdos nas disciplinas do ensino fundamental e médio", explica. (LORENZONI, 20/02/2008).

As decisões oficiais geradas pela repercussão midiática em Salvador impeliram a imprensa a continuar investigando os entraves para que a Lei se efetive. A questão foi abordada por Victor Pamplona ao entrevistar o coordenador de Educação Profissional da Secretaria Estadual da Educação, Carlos Alberto Menezes, logo após uma reunião do coordenador com representantes das secretarias da Cultura e promoção da Igualdade Racial, mediada pela presidente do Conselho Estadual de Educação Renée Albagli:

na Secretaria da Educação, responsável pela mudança do currículo nas 1.870 escolas da rede estadual, um grupo de trabalho chefiado pelo coordenador de Educação Profissional, Carlos Alberto Menezes, enviou ao secretário Adeum Sauer a proposta de um "plano de implantação" do ensino da cultura afro. Após ouvir representantes das pastas da Cultura e Promoção da Igualdade Racial, o programa deverá ser lançado. “O novo governo não começou do zero. A secretaria já havia participado do fórum nacional para implantação da lei. Faltava criar um documento e fazer um ato político", explica Menezes, referindo-se por último à cerimônia na qual o governo estadual pretende sinalizar o início do processo na prática, ainda sem data marcada. Entrave - $O$ principal entrave é tornar os professores aptos a lidarem com novos assuntos e abordar velhos temas seguindo novas orientações, mas não há definição na secretaria sobre como isso vai ocorrer. Menezes diz que a proposta elaborada pelo grupo de trabalho prevê a realização de "fóruns com entidades e aproveitamento da estrutura do IAT [Instituto Anísio Teixeira]", dentro da 
perspectiva de proporcionar "especialização e formação continuada". "Do ponto de vista pedagógico, é importante sensibilizar as universidades do Estado para a formação de professores", sugere Renée Albagli. (PAMPLONA, 12 de maio de 2007)

Os impactos gerados pelas repercussões midiáticas à intervenção do MP nas escolas provocam implicações na práxis pedagógica, práxis esta compreendida aqui como lugar de reflexão sobre teorias e práticas sócioeducacionais mediadas pela cultura e pelo seu contexto sócio-histórico, visando relações e ações dialógicas por meio das quais nos situamos e nos percebemos enquanto educadores e educantes.

\section{UMA ANÁLISE SOBRE AS IMPLICAÇÕES NA PRÁXIS PEDAGÓGICA.} ALGUMAS IMPRESSÕES.

Considero impossível não repercutir em sala de aula um tema tão efervescente como a repercussão midiática gerada pela intervenção do Ministério Público da Bahia, reagindo ao não cumprimento da Lei 10639/09 pelas escolas. Para isso devo retomar o problema da constituição da escola brasileira. Outra compreensão da práxis pedagógica refere-se ao momento de oportunizar reflexões sobre práticas, teorias e vivências educacionais e sociais por onde caminham as aspirações emancipatórias humanas. A esse respeito, recorro a Peter McLaren, (1997) na parte em que o autor contextualiza pedagogia crítica: estamos diante de uma nova sociologia da educação, que pressupõe variedades contralógicas importantes à análise positivista, não histórica e despolitizada. Para o autor, a categoria cultura comporta três subcategorias: cultura dominante, cultura subordinada e subcultura:

Cultura dominante refere-se ás práticas e representações sociais que afirmam os valores, interesses e preocupações centrais da classe social que controla a riqueza material e simbólica da sociedade. Os grupos que vivem relações sociais em subordinação à cultura dominante fazem parte da cultura subordinada.O grupo da subcultura pode ser descrito como um subconjunto das duas culturas-mãe(dominante e subordinada). (McLAREN, 1997, p.56)

Ainda em McLaren, observo a preocupação com a distinção das formas culturais definidas como símbolos e práticas sociais que expressam a cultura, tais como os encontrados na música, vestuário, comida, religião, dança e na educação. Dessa forma, acredito ser a escolarização uma forma cultural inter-relacionada com as configurações de ideologia, classes, raça e gênero. Minhas análises se fundamentam ainda na concepção de cultura 
como bem simbólico, portanto como prática de significação, exposta por Stuart Hall (2000). Esse autor diz que

os seres humanos são seres interpretativos, instituidores de sentidos. A ação social é significativa tanto para aqueles que a praticam quanto para os que a observam: não em si mesmas, mas em razão dos muitos e variados sistemas de significados que os seres humanos utilizam para definir o que significam as coisas e para codificar, organizar e regular sua conduta uns em relação aos outros. Estes sistemas ou códigos de significados dão sentido às nossas ações. Eles nos permitem interpretar significativamente as ações alheias. Tomados em seu conjunto, eles se constituem nossas "culturas". Contribuem para assegurar que toda ação social é "cultural", que todas as práticas sociais expressam ou comunicam um significado e, neste sentido, são práticas de significação. (HALL, 1977, p.16).

Com essa definição, evidencio minha preocupação com a percepção de normalidade cultural na escola. Penso que Nóvoa (1998) me orienta nesse sentido momentâneo. "As escolas são instituições de um tipo muito particular que não podem ser pensadas como qualquer fábrica ou oficina: a educação não tolera a simplificação do humano que a cultura da racionalidade empresarial sempre transporta" (p.16). Reflito em Bourdieu (1977) sobre o papel da escola como produtora e reprodutora das condições institucionais visando uma condição social normativa. Padronizada e sustentada em habitus como mediação universalizante, a escola está, portanto, dotada de razoabilidade social: em campo, no sentido de dar direção à produção científica e cultural; e, em práticas, traduzidas como resultado da relação apenas dialética entre uma situação e o habitus. Percebo nesse conceito de habitus uma estreita ligação com a importância midiática na repressão oportuna às escolas diante do descaso ao cumprimento da lei 10.639/03 e encontro na explicação a seguir uma possível motivação para esse fenômeno.

Para fechar a questão, atento para o que disse Gramsci (1981) a respeito de escola. Para esse autor, a escola adquire em sua natureza social uma grandeza somente comparada à igreja, porque em potencial, todos são convencionados à cultura escolástica. Como organização hegemônica, a escola se estabelece no poderio instrumental, e dessa forma assume importância nuclear na difusão de ideologias que tanto legitimam o status quo quanto o questionam. No caso da escola brasileira, as ideologias comportam o binômio ser branco e ser cristão, excluindo outras formações identitárias, negando assim, outras formas de ser e de viver da condição humana.

A validade da série de reportagens de $A$ Tarde On line e Ibahia, observando seu caráter de denúncia sobre a resistência à Lei 10.639/03, pode ser 
associada positivamente a outras repercussões para os meios acadêmicos: 1) inspira novos debates sobre os entraves à aplicabilidade da Lei; 2) expõe nuances para novas reflexões sobre sociedade, cultura, poder, hierarquia racial e desigualdades; 3 ) não se trata de demonizar a mídia ou, em outro pólo, atribuir às reportagens as tomadas de posição necessárias à escola em relação a aplicabilidade da Lei 10.639/03. Compreendo que o pano de fundo, conforme análise deste texto é, também, de ordem macro, sociológica, histórica e política, e de engrenagem governamental executiva. Assim sendo, suscita o debate, novas e possíveis reflexões sobre formação de professores, responsabilidades pedagógicas e concepções de escola e educação, especialmente porque a escola, mas não somente a escola, historicamente segregou saberes de raízes afro-brasileiras e indígenas, ajudando a edificar as diferenças desiguais.

\section{CONCLUSÕES}

Este artigo foi produzido a partir da pesquisa de mestrado no Programa de Pós-graduação em Educação da Universidade Federal da Bahia, intitulada A Cultura Corporal e a Lei no 10.639/03: um estudo sobre os impactos da lei no ensino da Educação Física nas escolas de Salvador, apresentada em dissertação aprovada por banca examinadora em 28 de novembro de 2008. O trabalho foi apoiado pelo grupo HCEL/Cnpq, História da Cultura Corporal, Educação, Esporte, Lazer e Sociedade do PPGE/FACED/UFBA. Em linhas gerais, este texto não integra a dissertação, contudo, foi sistematizado em função da relevância argumentativa para a compreensão do objeto.

Considero louvável o papel exercido pelos promotores do Ministério Público ao fiscalizarem in loco a situação da Lei 10.639/03 nas escolas públicas e privadas. Trata-se de um dos primeiros diagnósticos sobre a aplicação dessa lei. O fato de um órgão regulador de cunho jurídico intervir na escola mostra, de certa forma, que a clausura e intocabilidade da escola tornam-se frágeis quando a comunidade resolve valer-se de instrumentos externos, como a imprensa e o próprio Ministério Público.

A tensão provocada pela decisão dos promotores, se por um lado constrange a estrutura escolar, por outro fortalece a Lei 10.639/03 como instrumento legislativo. Isso pode ser ruim ou bom, a depender dos efeitos produzidos. Considero o episódio marcante historicamente e extremamente grave do ponto de vista institucional, vez que as vistorias do Ministério Público puseram em xeque a lisura do próprio poder público ao cumprir determinações de documentos por ele mesmo formulados. No caso da Lei 10.639/03, embora tenha sido este documento uma construção histórico- 
política assumida pelo Movimento Negro, não se pode abrir mão de seu cunho legislativo, sob pena de ele tornar-se letra morta. Em sendo assim, todos os esforços devem ser somados para que a lei 10.639/03 seja cumprida tal como foi formulada, alterar a lei máxima da educação brasileira (LDBEN) e os Parâmetros Curriculares Nacionais para atingir os projetos políticos e os currículos escolares, embora se reconheça que mecanismos extracurriculares e para além dos muros da escola também são necessários à efetivação da validade política da Lei.

Além das reflexões produzidas pelo interesse da mídia na implementação da Lei 10.639/03 na capital da Bahia, as reportagens conseguiram chamar a atenção para o problema da resistência à aplicação da Lei, especialmente nas escolas privadas. O propósito das peças jornalísticas se efetivou na polêmica, desenrolou-se nos debates acadêmicos e culminou no bom uso da mídia pelas fontes dependentes: a comunidade escolar. Dessa forma a comunidade exerceu posição política legítima de denunciar.

Ao trazerem a escola para a grande mídia, as peças jornalísticas ajudam a entender o ambiente escolar como lócus de relações sociais assimétricas tensas e não apenas como espaço formador ou instrutor de pessoas. Afirmo que a produção e difusão do conhecimento, de matriz ocidental hegemônica, têm forte impacto no senso comum, o que valoriza este momento de embate por uma epistemologia diversa, uma nova cultura escolar e uma relação mais humana e dialógica entre sociedade e pedagogia.

REPERCUSSIONS OF LAW 10.639/03 IN THE MEDIA IN SALVADOR, BAHIA: AN ANALYSIS OF THE IMPLICATIONS FOR TEACHING PRACTICE

ABSTRACT: this paper addresses the repercussions in the media of the process of the obligatory implementation of Law 10.639/03 in the curricula of elementary and high schools in the State of Bahia. After clippage, certain reports published in two of Salvador's most significant electronic journals, ibahia and A Tarde on-line, were examined. These highlight the situation of schools in Bahia in the context of the Bahia Public Prosecutor's office inspection of enforcement of the law, which created a tense, interventionist situation. This paper proposes a reflection on the episode, showing that the social and racial inequality reproduced in the school remains unchanged. In addition, it suggests a reflection on the importance of combating all forms of discrimination and prejudice both within and beyond the school, factors addressed by the mainstream media as a reflex of Law 10.639/03. KEYWORDS: School. Legislation. Media. 


\section{NOTAS}

1. A preparação deste texto implicou uma revisão das análises dos dados colhidos nos sites de notícias selecionados, com fins de ampliação do foco proposto para o Concurso da ANPED. Essa revisão, com atualização de estatísticas, novas leituras de análises e ampliação do volume de texto garante as exigências constantes no edital, embora parte da temática, especialmente seus dados já tenham sido debatidos e divulgados em eventos educacionais, momentos de aula e revistas. Acrescentei nessa revisão novas bibliografias e outros pontos de vista, expostos principalmente em seus argumentos conclusivos, além de reflexões constantes na minha dissertação de mestrado defendida em 2008 na Faculdade de Educação da Universidade Federal da Bahia. Este artigo teve a orientação da Professora Doutora Maria Cecília de Paula Silva e apoio do grupo de pesquisa HCEL/UFBA. (História da Cultura Corporal, Lazer, Esportes, Educação e Sociedade).

2. Clipagem: recurso jornalístico de base organizacional, usado para catalogar produções midiáticas com fins de análise e repercussão. Muito usado nas assessorias de comunicação.

3. A palavra lei aparece iniciada em letra maiúscula toda vez que houver referência ao seu formato documental. Quando o termo é usado em letras minúsculas, refere-se a "lei" de modo geral, substantivamente.

4. Refiro-me à normalidade nas coberturas jornalísticas diárias da grande imprensa sobre a escola.

5. O termo ambiente é aqui utilizado para falar de escola como espaço físico delimitado por funções institucionais e hierárquicas, relacionadas à legislação. Difere, portanto, do termo escola em sentido mais ampliado como espaço comum de convivência cultural, aprendizado, política e emancipação.

6. Herbert Marshall McLuhan, filósofo e educador canadense. Teórico dos meios de comunicação foi precursor dos estudos midiológicos.

7. Mutation, livreto escrito por McLuhan, publicado em 1990, dez anos após sua morte. Faz parte da coleção Médium mame de Paris, França.

8. Referimo-nos a chamada mídia menor do ponto de vista comercial, tecnológico de rede e publicitário, a exemplo das rádios e jornais comunitários, ou serviços comunitários de alto falantes.

9. Os dados dessa realidade estão publicados na Dissertação de Mestrado intitulada "A Cultura Corporal e a Lei n 10.639/03:um estudo sobre os impactos da Lei no ensino da Educação Física em Salvador, aprovada na Faculdade de Educação da Universidade Federal da Bahia em 2008. Este artigo foi produzido para integrar a dissertação e, retirado por determinação da orientação da versão final dissertativa. Portanto, considera-se que esses dados estão acoplados à dissertação não necessitando de citação da obra,como referência desses dados. Isto afasta qualquer suspeita sofre 
possíveis plágios de termos, vez que se trata de um fragmento de corpo de uma dissertação completa.

10. Os números do Produto Interno Bruto (PIB) utilizados referem-se aos dados de 2003, do IBGE. O indicador PIB mede a produção geral do País.

11. Dados coletados pela Companhia de Desenvolvimento Urbano do Estado da Bahia (CONDER).

12. Termo atribuído às regiões de maior concentração de ricos em Salvador ou bairros onde residem famílias mais tradicionais e ricas.

13. Ligamos este termo às lutas, ideologias e toda forma de resistência à discriminação de cor no Brasil. Não se refere de forma alguma ao conceito biológico de raça, inexistente, cientificamente.

14. Pré-pauta, situação em que a assessoria de imprensa de determinados órgãos ou entidades, no caso específico, o MP, revelam com antecedência os locais e assuntos referentes à ação da própria entidade ou órgão, favorecendo o acompanhamento de jornalistas e/ou outros interessados.

\section{REFERÊNCIAS}

BOURDIEU, Pierre. Cultural reproduction and social reproduction. In: KARABEL, J.;

BRASIL. Lei n. 11. 465, 10 de março de 2008. Altera a Lei no 9.394, de 20 de dezembro de 1996, modificada pela Lei no 10.639, de 9 de janeiro de 2003,que estabelece as diretrizes e bases da educação nacional, para incluir no currículo oficial da Rede de Ensino a obrigatoriedade da temática "História e Cultura Afro-Brasileira", e dá outras providências. Disponível em: < <http://www6.senado.gov.br/legislac. action?id=236171> Acesso em: 15 de março de 2008.

BRASIL. Lei n. 10.639, 9 de janeiro de 2003. Altera a Lei no 9.394, de 20 de dezembro de 1996, que estabelece as diretrizes e bases da educação nacional, para incluir no currículo oficial da Rede de Ensino a obrigatoriedade da temática "História e Cultura Afro-Brasileira", e dá outras providências. Disponível em: < <http://www6.senado.gov. br/legislac. action?id=2> Acessado em 02 de junho de 2007.

DÁVILA, Jerry. Diploma de brancura: política social e racial no Brasil: 1917-1945. Tradução Cláudia Santana Martins. São Paulo: UNESP, 2006.

GADOTTI, M.. A questão da educação formal/não formal. [S.I: s.n.], 2005. Documento apresentado no evento Droit à l'éducation: solution à tous les problèmes ou problème sans solution? Institut International des droits de l'enfant (IDE), Sion (Suisse), 18 a 22 de outubro, 2005. Disponível em: <http://www.paulofreire.org/twiki/pub/Institu/ Sublnstitucional1203023491/t003Ps002/Educacao_formal_nao_formal_2005.pdf>. Acessado em 5 novembro de 2006. 
GRAMSCI, A.. Concepção Dialética da História. 4. ed,. Trad. Carlos Nelson Coutinho. Rio de Janeiro: Civilização Brasileira, 1981.

HALSEY, A. H. (Eds.). Power and ideology in education. New York: Oxford University Press, 1977.

HALL, S.. Quem precisa da identidade? In: SILVA, TomazTadeu (org. e trad.). Identidade e diferença: a perspectiva dos estudos culturais. Petrópolis: Vozes, 2000. p. 103-133.

IBGE. Produto Interno Bruto (PIB). 2005. Disponível em: <http://www.ibge.gov.br/ home/>. Acesso em: 23 fev. 2008.

LIMA, L. O. Mutações em educação segundo McLuhan. 19. Ed. Petrópolis: Vozes, 1987. LORENZONI, I. Estudo da história afro-brasileira deve ser incluído em cursos de literatura.< http: //portal.mec.gov.br/index.php?option=com_content\&task=view\&id=9922>, acessado em 20 de fevereiro de 2008.

MCLAREN, P. A Vida nas escolas: uma introdução à pedagogia crítica nos fundamentos da educação. Trad. Lucia Pallanda Zimmer, Porto Alegre: Artes Médicas, 1997.

NEUMANN, L. Educação e comunicação alternativa. Petrópolis: Vozes, 1990.

NÓVOA, A. Formação de professores. 2. ed. São Paulo: Unesp, 1998.

PAMPLONA, V. Bahia regulamenta o ensino de cultura afro com atraso de 4 anos: escolas privadas não temem inquérito do MP. PORTAL a tarde on line, <http://www.atarde. com.br, acessado em 12 de maio de 2007>.

PORTAL ibahia. MP propõe implantação da cultural afro-brasileira nas escolas. <http:// ibahia.globo.com/, acessado em 21 de novembro de 2007>.

AnÁlIA de Jesus MOREIRA é graduada em Educação Física pela Universidade Católica do Salvador (UCSAL), mestre e doutoranda pelo programa de pós-graduação em Educação da Faculdade de Educação da Universidade Federal da Bahia e professora assistente do Centro de Formação de Professsores da Universidade Federal do Recôncavo da Bahia (UFRB). Integra o grupo de Pesquisa HCEL (História da Cultura Corporal, Educação, Lazer e Sociedade, da Faculdade de Educação da UFBA.

E-mail:nlmoreira722@gmail.com 
